\title{
A Study of Antenna System for High Order MIMO Device
}

\author{
Zhaoliang Chen, ${ }^{1}$ Wen Geyi, ${ }^{1}$ Ming Zhang, ${ }^{2}$ and Jun Wang ${ }^{2}$ \\ ${ }^{1}$ Research Center of Applied Electromagnetics, Nanjing University of Information Science and Technology, Nanjing 210044, China \\ ${ }^{2}$ Huawei Technologies Co., Ltd., No. 360, Jiangsu Road, Binjiang District, Hangzhou 310052, China \\ Correspondence should be addressed to Zhaoliang Chen; 1060400798czl@sina.cn
}

Received 16 December 2015; Revised 4 February 2016; Accepted 10 February 2016

Academic Editor: Xianming Qing

Copyright (C) 2016 Zhaoliang Chen et al. This is an open access article distributed under the Creative Commons Attribution License, which permits unrestricted use, distribution, and reproduction in any medium, provided the original work is properly cited.

\begin{abstract}
Three types of compact MIMO (Multiple-Input Multiple-Output) antenna systems with four and six elements for mobile handsets are studied in this paper. The MIMO antenna system is built on a FR4 substrate of the dimensions $136 \mathrm{~mm} \times 68.8 \mathrm{~mm} \times 1 \mathrm{~mm}$. The antenna element is a folded planar inverted-F antenna with added resonating branches wound on a small dielectric cube of the dimensions $10 \mathrm{~mm} \times 10 \mathrm{~mm} \times 5 \mathrm{~mm}$, which is the smallest volume so far reported covering the frequency bands $1880 \mathrm{MHz}-$ $1920 \mathrm{MHz}$ and $2300 \mathrm{MHz}-2620 \mathrm{MHz}$ for GSM1900, LTE2300, 2.4-GHz WLAN, and LTE2500. The effects of element numbers and configurations on the system performance are investigated. More than $10 \mathrm{~dB}$ isolations have been achieved by properly designing the antenna elements through the use of the pattern diversity without using decoupling circuits. The envelope correlation coefficients among the elements, the mean effective gains, the efficiencies, and the multiplexing efficiencies of the elements are also discussed.
\end{abstract}

\section{Introduction}

Nowadays, wireless communication technology is developing rapidly with the goals of achieving large channel capacity, high transmission rate, and high reliability. Multiple-input multiple-output (MIMO) arrays have been recognized as a key technology to reach the goals. In a multiple channel environment, the MIMO system can increase the transmission rate and channel capacity without sacrificing additional frequency spectrum and transmitted power [1], and a MIMO antenna system can improve the mobile communication quality when it has good isolation and envelope correlation coefficient (ECC) among its antenna elements simultaneously. Due to the limited space of the mobile terminals, the volume occupied by the antenna elements and the distance between them must be small, which propose major challenges for a MIMO antenna system to realize wideband in frequency, miniaturization in size, and high isolation among the antenna elements [1-3]. In the existing research articles, the number of antenna elements deployed in the MIMO systems investigated ranges from two to eight with different goals in mind: some of them are primarily for achieving the wide bandwidth $[4,5]$; some for the miniaturization of antenna element size [6, 7]; and some for the high isolation among antenna elements through a variety of methods [8, 9]. It is rare to see a report that solves all these problems simultaneously.

In MIMO antenna designs, reducing mutual coupling and correlation coefficient between closely packed antenna elements is one of the key challenges. For antenna elements in close proximity, the radiated energy from one element can be delivered to other elements through near field coupling or conductive coupling (via the common ground plane). As the number of antenna elements increases, the radiation efficiency of some antenna elements may drop quickly due to the mutual coupling [10]. For this reason, a number of methods have been developed for improving the isolation and correlation coefficient between closely packed MIMO antenna elements in small portable handsets. These include etching slots on the ground plane, using electromagnetic band gap (EBG) structures, deploying decoupling or matching networks, introducing parasitic structures, properly placing the antenna elements, changing radiation patterns, and introducing neutralization line [11-29]. Most of these methods would increase the complexity of the system and require considerable design effort.

In this paper, MIMO antenna systems for handset applications with four and six elements for a mobile handheld 


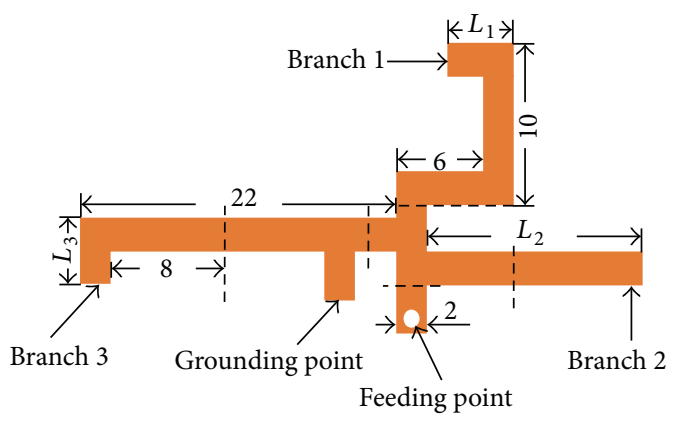

Unit: (mm)

(a)

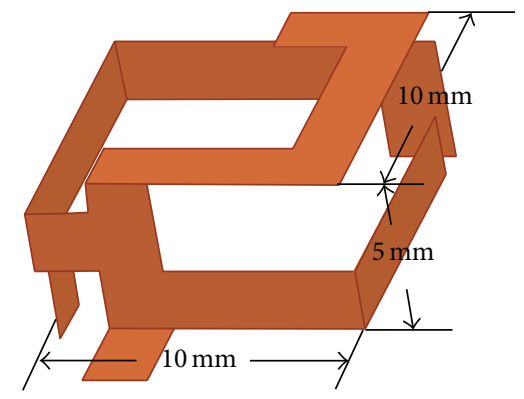

(b)

Figure 1: (a) Geometry of the antenna element; (b) 3D graph of the element.

device of small form factor have been investigated. An attempt is made to achieve good isolation, wide bandwidth and miniaturization simultaneously on a very compact platform, and a FR4 substrate of the dimensions $136 \mathrm{~mm}$ $\times 68.8 \mathrm{~mm} \times 1 \mathrm{~mm}$. The antenna element adopted is the three-dimensional inverted-F antenna with added resonating branches wrapped around a very small dielectric cube of dimensions $10 \times 10 \times 5 \mathrm{~mm}^{3}$, which is the smallest volume so far that covers the required frequency bands for GSM1900, LTE2300, 2.4-GHz WLAN, and LTE2500. The MIMO antenna systems do not involve any decoupling circuits and have achieved a good isolation throughout the whole frequency band by properly designing the antenna elements and using the pattern diversity. The envelope correlation coefficients, the mean effective gains (MEGs), and the multiplexing efficiency are calculated based on the measured data. The results indicate that the envelope correlation coefficient between any two elements of the MIMO antenna is less than 0.5 ; the maximum gain of the antenna is more than $1 \mathrm{~dB}$; the difference between the mean effective gains of the antenna elements is less than $3 \mathrm{~dB}$.

\section{Design of Four-Element MIMO Antenna System}

2.1. Specifications of Antenna System. The unfolded view of the antenna element with detailed dimensions is shown in Figure 1. The antenna is folded along the dashed lines and is then wrapped around a dielectric cube of relative

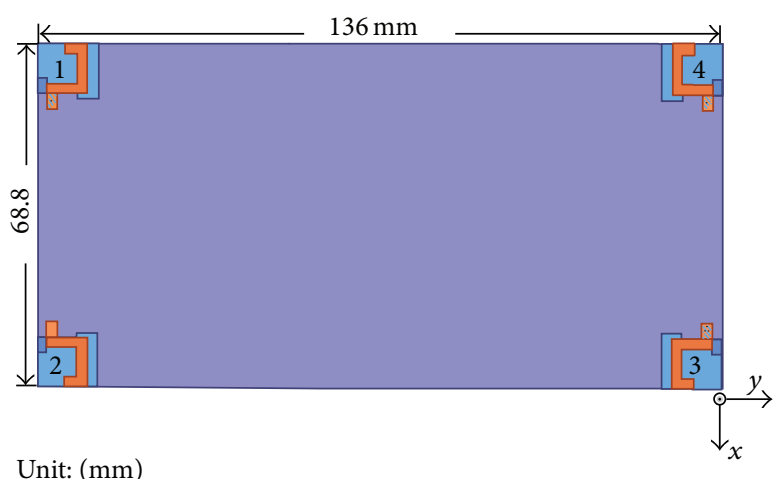

Figure 2: The MIMO antenna system.

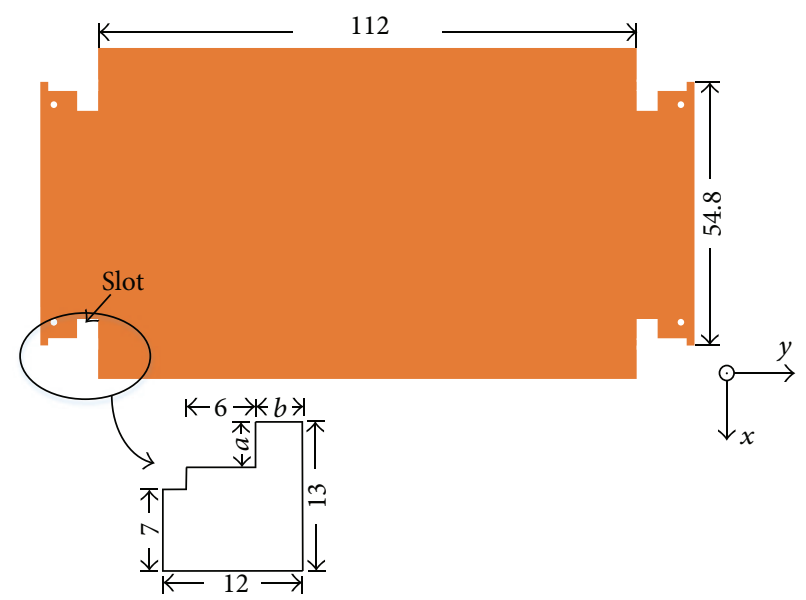

Unit: (mm)

FIgURE 3: The ground of PCB.

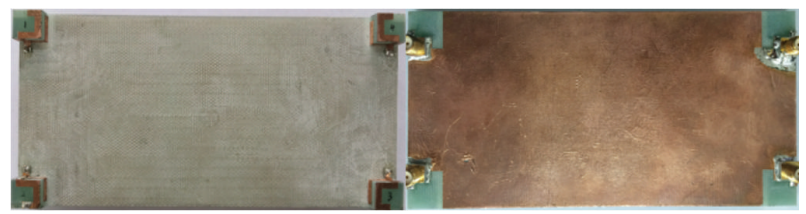

FIGURE 4: Photograph of the fabricated four-element MIMO system.

permittivity 4.4 and loss tangent 0.02 . The design introduces several radiating branches, independent of each other to some degree, to control different frequency bands [30, 31]. The branches 1 and 3 are mainly used to control the band $1880-1920 \mathrm{MHz}$; the slot of the ground (see Figure 3) is part of the antenna and is used to achieve the rest of the frequency bands mentioned above; branch 2 affects both low and high frequencies to some extent. The antenna elements are placed at the four corners of the FR4PCB of the size $136 \mathrm{~mm} \times 68.8 \mathrm{~mm} \times 1 \mathrm{~mm}$ with relative permittivity 4.4 and loss tangent 0.02 . Figures 2 and 3 show the entire structure of the MIMO antenna system and the ground of the PCB, respectively. Figure 4 is the photograph of the fabricated MIMO antenna system. 
TABLE 1: Mean effective gains of the antennas.

\begin{tabular}{|c|c|c|c|c|c|}
\hline Frequency $(\mathrm{GHz})$ & $\Gamma(\mathrm{dB})$ & MEG1 (dBi) & MEG2 (dBi) & MEG3 (dBi) & MEG4 (dBi) \\
\hline \multirow{2}{*}{1.9} & 0 & -6.4 & -6.2 & -6 & -6.4 \\
\hline & 6 & -6.3 & -6.1 & -6.3 & -6.2 \\
\hline \multirow{2}{*}{2.6} & 0 & -8.1 & -8 & -8.2 & -8 \\
\hline & 6 & -7.8 & -7.9 & -8 & -8.1 \\
\hline
\end{tabular}

\subsection{Parameters Analyses Based on Simulation and Measure-} ment. To reveal the functions of the resonating branches and the slot (see Figures 1(a) and 3), Figures 5(a)-5(d) show the simulated reflection coefficients of the antenna element for different values of $L_{1}, L_{2}, L_{3}, a$, and $b$. The antenna has two resonant frequencies, and after optimization with Ansys HFSS, the optimized values are obtained as follows: $L_{1}=4.1 \mathrm{~mm}, L_{2}=15 \mathrm{~mm}, L_{3}=4 \mathrm{~mm}, a=4 \mathrm{~mm}$, and $b=4 \mathrm{~mm}$. The measured $S$-parameters of the four-element MIMO system are shown in Figure 5(e). Note that the measured $-10 \mathrm{~dB}$ impedance bandwidth covers the required frequency band, and the mutual coupling is lower than $-10 \mathrm{~dB}$ across the entire frequency band. Due to the symmetry of the arrangement of the antenna elements, only the $S_{1 i}(i=$ $1,2,3,4)$ are plotted.

Figures 6(a) and 6(b) are the current distributions along the controlling branches for $1.9 \mathrm{GHz}$ and $2.35 \mathrm{GHz}$, respectively.

The ECC and MEGs are important performance criteria to evaluate the MIMO system [32-35]. The envelop correlation coefficients between antennas $i$ and $j$ can be calculated by [34]

$$
\rho_{e}=\frac{\left|\iint_{4 \pi}\left[\mathbf{F}_{1}(\theta, \varphi) \cdot \mathbf{F}_{2}(\theta, \varphi)\right] d \Omega\right|^{2}}{\iint_{4 \pi}\left|\mathbf{F}_{1}(\theta, \varphi)\right|^{2} d \Omega \iint_{4 \pi}\left|\mathbf{F}_{2}(\theta, \varphi)\right|^{2} d \Omega}
$$

where $\mathbf{F}_{i}(\theta, \varphi)$ is the field radiation pattern of the antenna system when port $i$ is excited and the dot d denotes the Hermitian product.

The field radiation patterns are obtained from the SATIMO Star Lab chamber. The envelope correlation coefficients of the MIMO antenna system are calculated from the measured patterns in two different scenarios, the uniform $3 \mathrm{D}$ and the Verizon LTE test plan. The uniform 3D test plan is based on the uniform environment, and the Verizon LTE test plan is based on LTE-A MIMO channel model, as illustrated in Figure 7 [36-38]. The measured ECCs are shown in Figure 8. It can be seen that the ECCs are lower than 0.1 in both scenarios.

The simulated and measured radiation patterns in the $x z$-plane and $y z$-plane for the antenna element are shown in Figure 9. The radiation patterns are obtained under the condition that one element is excited while the others are terminated in a matching load. The solid and dashed lines denote the simulated and measured results, respectively. The black and red lines, respectively, represent the $\theta$ and $\varphi$ polarized components of the antenna power gain.

The MEG is defined as the ratio of the mean received power to the mean incident power of the antenna. A series
TABle 2: Antenna efficiency.

\begin{tabular}{lcc}
\hline Frequency $(\mathrm{GHz})$ & Efficiency $(\%)$ & Multiplexing efficiency $(\mathrm{dB})$ \\
\hline 1.9 & 52 & -6.13 \\
2.6 & 70 & -5.12 \\
\hline
\end{tabular}

of reasonable assumptions may be adopted to simplify the calculation $[39,40]$. Based on these approximations, the MEG can be expressed as [41]

MEG

$$
=\frac{1}{2 \pi} \int_{0}^{2 \pi}\left[\frac{\Gamma}{\Gamma+1} G_{\theta}\left(\frac{\pi}{2}, \varphi\right)+\frac{1}{\Gamma+1} G_{\varphi}\left(\frac{\pi}{2}, \varphi\right)\right] d \varphi,
$$

where $G_{\theta}$ and $G_{\varphi}$ are the $\theta$ and $\varphi$ polarized components of the antenna power gain pattern; $\Gamma$ is the cross-polarization discrimination (XPD). In this paper, $\Gamma$ is chosen as $0 \mathrm{~dB}$ and $6 \mathrm{~dB}[42,43]$, which are the average values, respectively, for an indoor $(0 \mathrm{~dB})$ and an urban $(6 \mathrm{~dB})$ fading environment. The MEGs are listed in Table 1 and are obtained from the measured data. Due to the symmetry, the MEGs of four elements are almost the same at the same frequency.

The efficiencies of the antenna elements measured at two typical frequencies are shown in Table 2. The efficiencies are obtained from the SATIMO Star Lab chamber. Note that the efficiency is lower at the GSM1900 than other bands due to the absorption of the adjacent elements. The multiplexing efficiency is defined as [44-46]

$$
\eta_{\text {mux }}=\frac{P_{T, 0}}{P_{T}}
$$

where $P_{T, 0}$ and $P_{T}$ denote the required power for achieving the same capacity performance with the reference antenna and the MIMO AUT [44]. For high SNRs, $\eta_{\operatorname{mux}}$ can be obtained as [45]

$$
\tilde{\eta}_{\text {mux }}=\lim _{P_{T} \rightarrow \infty} \eta_{\text {mux }}=\frac{P_{T, 0}}{P_{T}}=\frac{\operatorname{det}(R)^{1 / M}}{\operatorname{det}\left(R_{0}\right)^{1 / M}},
$$

where $R$ and $R_{0}$ are the receive correlation matrices when using the MIMO AUT and the reference antenna in the same propagation channel; $M$ denote the number of the antenna elements. The multiplexing efficiencies with the uniform 3D scenario are evaluated as shown in Table 2.

\section{Design of Six-Element MIMO Antenna System}

In a MIMO system, increasing the number of antenna elements can enhance the channel capacity and the data 


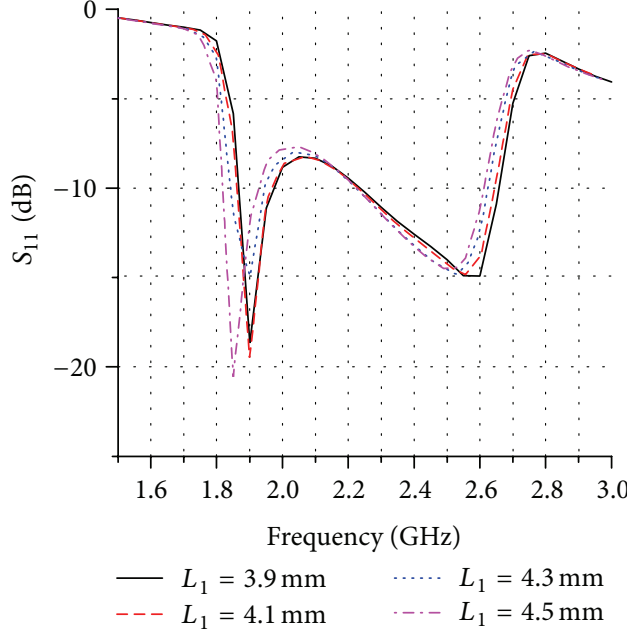

(a)

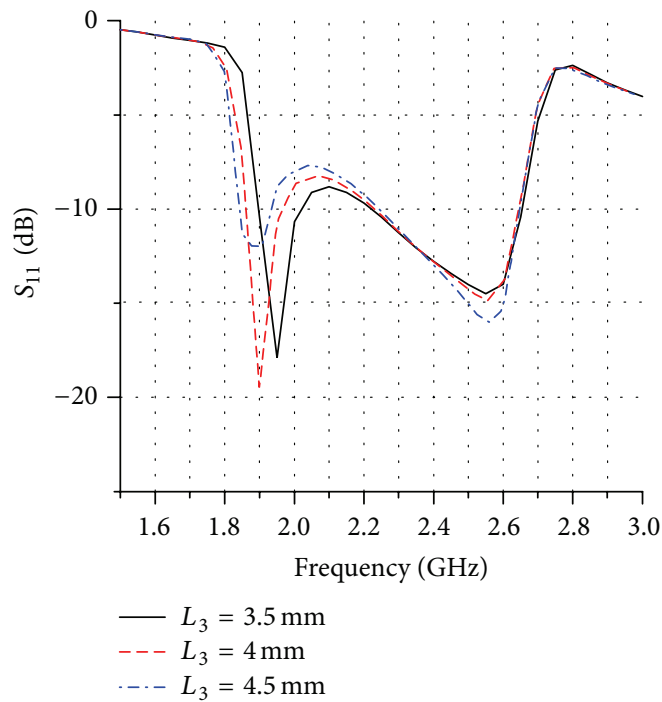

(c)

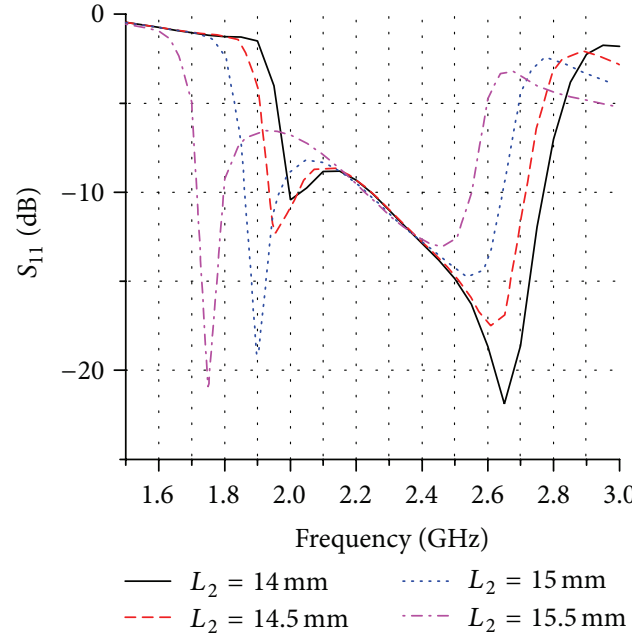

(b)

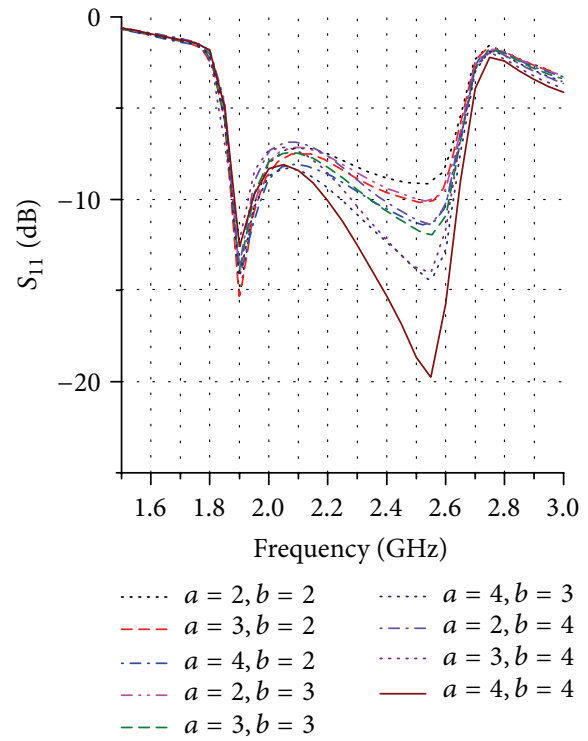

(d)

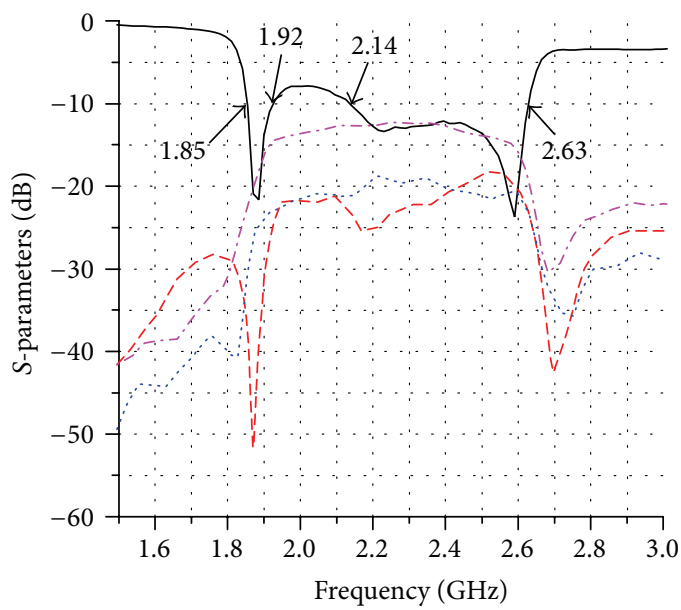

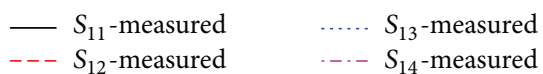

(e)

Figure 5: (a)-(d) $S$-parameters with different $L_{1}, L_{2}, L_{3}, a$, and $b$; (e) measured $S$-parameters. 


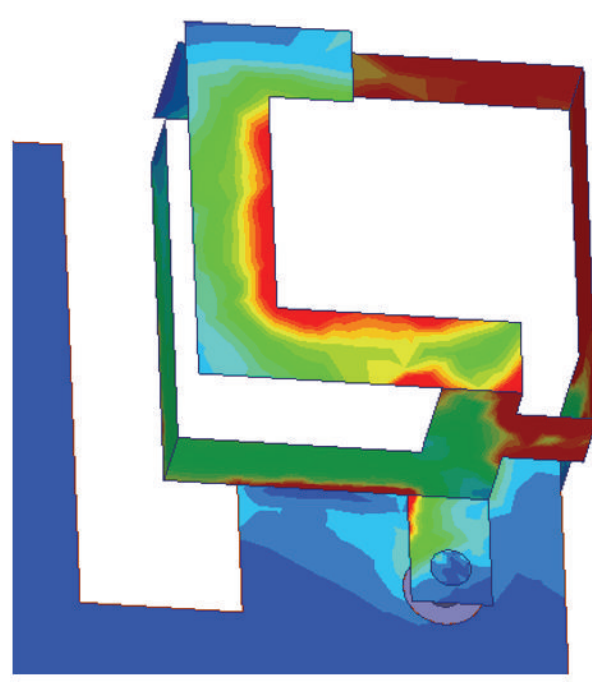

(a)

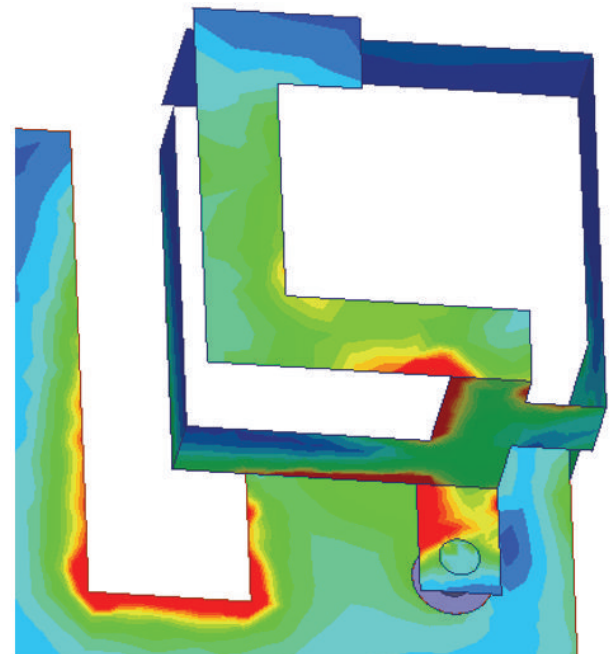

(b)

Figure 6: Simulated surface current distributions of the antenna element. (a) At 1.9 GHz; (b) at 2.35 GHz.

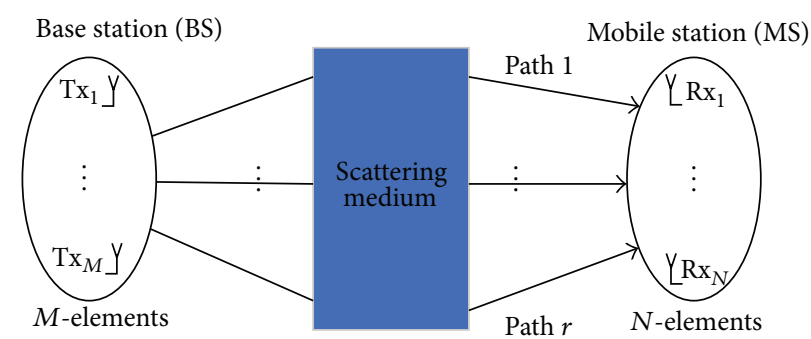

FIGURE 7: The MIMO channel model.

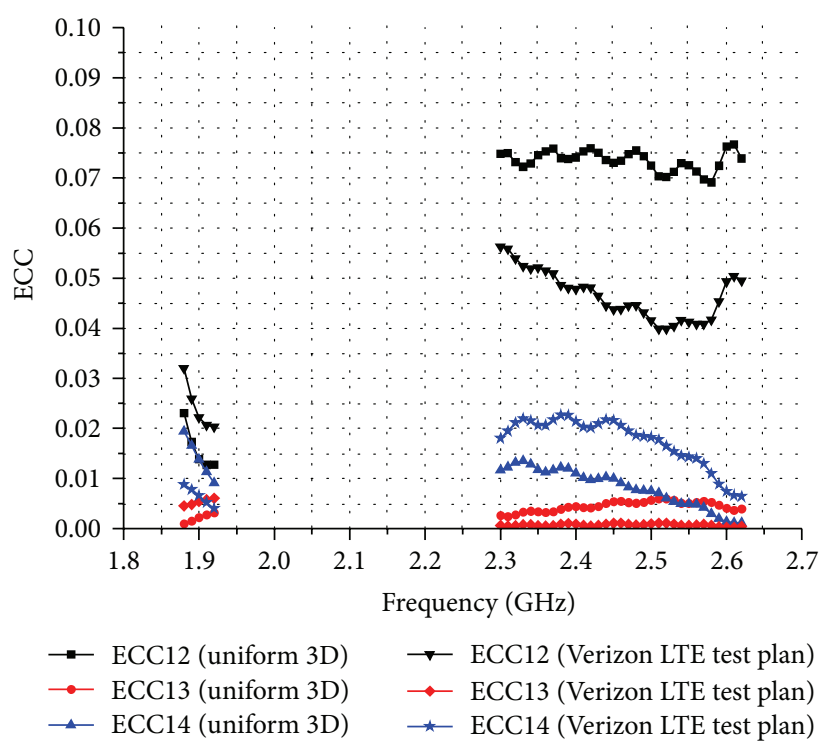

FIGURE 8: Envelope correlation coefficient between the antennas.

transmission rate, and the performance of the system can be improved accordingly. Now the number of antenna elements is increased from four to six and two different arrangements will be examined. The first one is shown in Figure 10(a), where two antenna elements are introduced in the middle of the long sides of the substrate and are placed symmetrically about $y$-axis. From the measured $S$-parameters (see Figure 12(a)), the isolations between antennas 3,6 and 4,5 are higher than 

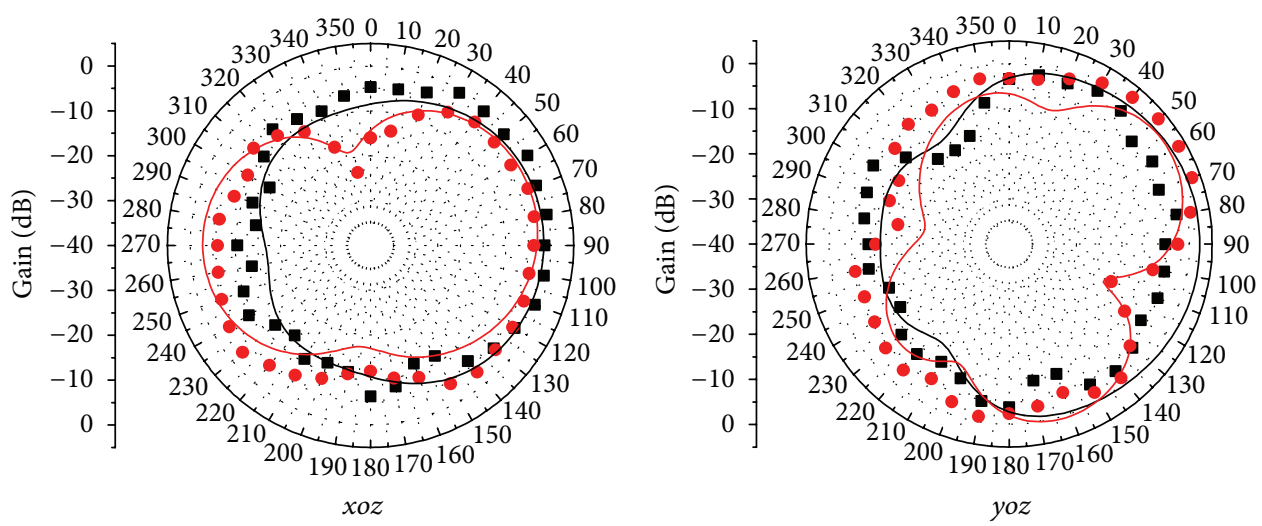

- $G_{\varphi}$-measured $-G_{\varphi}$-simulated

- $G_{\varphi}$-measured $-G_{\varphi}$-simulated

- $G_{\theta}$-measured $-G_{\theta}$-simulated

$$
\text { - } G_{\theta} \text {-measured }-G_{\theta} \text {-simulated }
$$

(a)
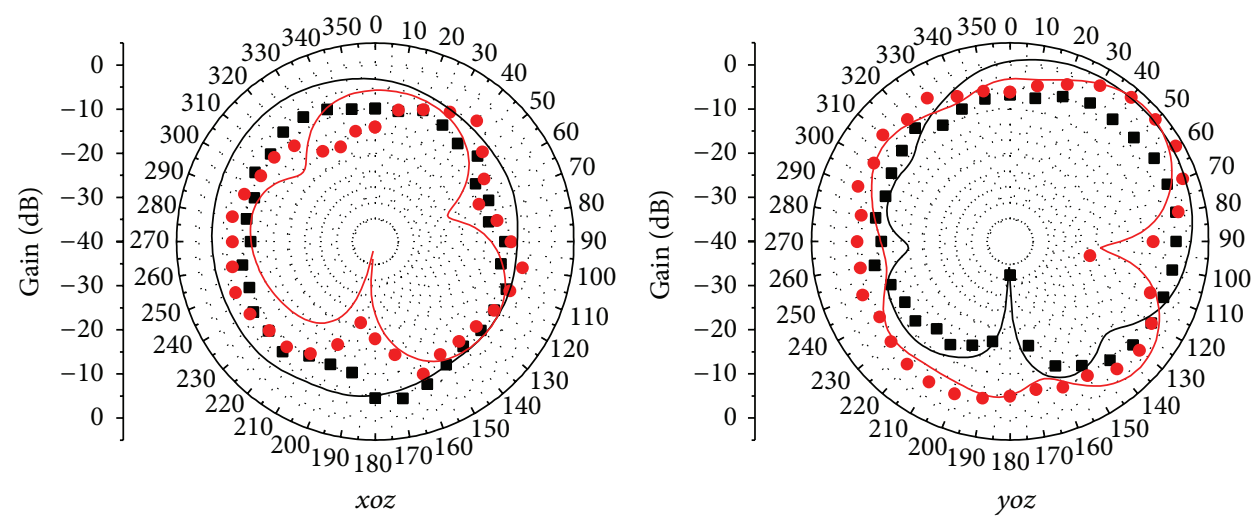

- $G_{\varphi}$-measured $-G_{\varphi}$-simulated

- $G_{\theta}$-measured $-G_{\theta}$-simulated

- $G_{\varphi}$-measured $-G_{\varphi}$-simulated

- $G_{\theta}$-measured $-G_{\theta}$-simulated

(b)

Figure 9: Measured and simulated radiation patterns. (a) At $1.9 \mathrm{GHz}$; (b) at $2.6 \mathrm{GHz}$.

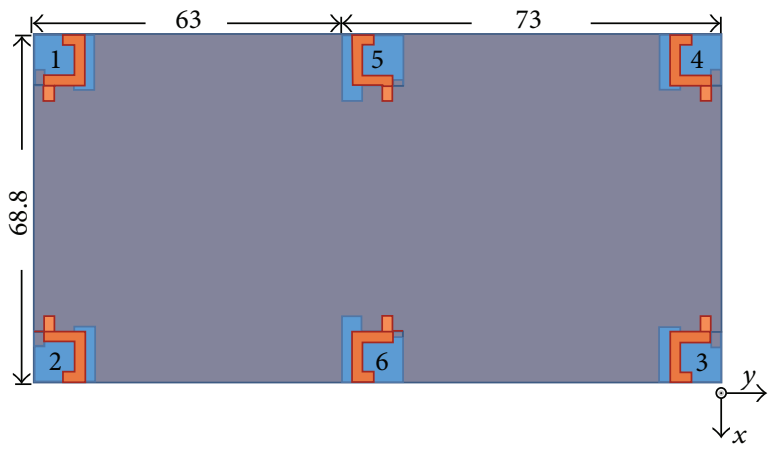

Unit: (mm)

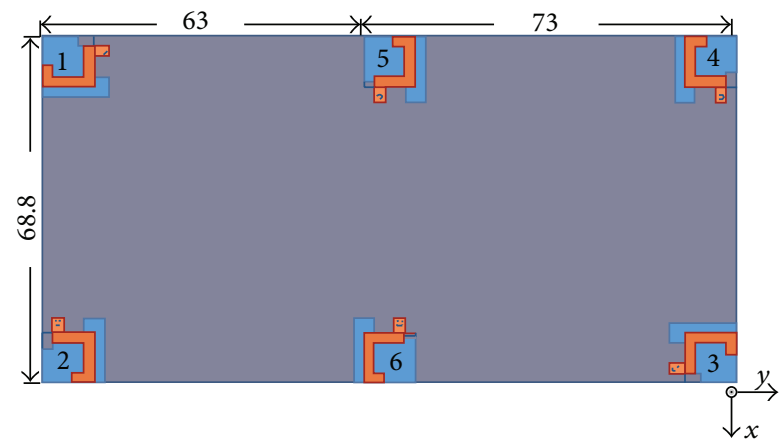

Unit: (mm)

(a)

(b)

FIgURE 10: The six-element MIMO system.

$-10 \mathrm{~dB}$ and cannot meet the practical requirement. From simulation, we find that the radiation intensity of antennas 3 and 4 is very strong along the negative direction of the $y$ axis. As a result, the radiated energy from antennas 3 and 4 is coupled to antenna 6 and 5, respectively. For this reason, we rearrange the antenna elements so that they are rotationally symmetric about $z$-axis to reduce the mutual coupling due to the radiation, as illustrated in Figure 10(b). Figure 11 is 


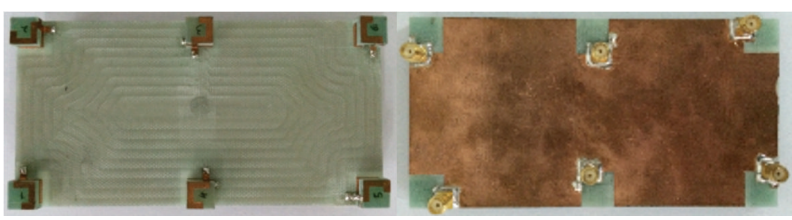

FIGURE 11: Photograph of the fabricated six-element MIMO system.

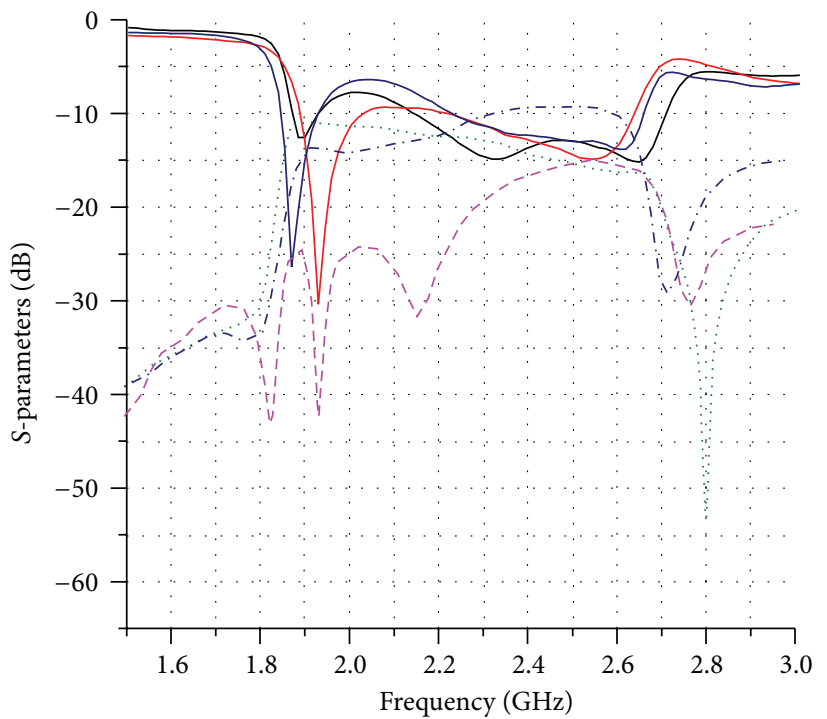

- $S_{11}$-measured

- $S_{44}$-measured

- $S_{55}$-measured
- - $S_{12}$-measured

…. $S_{15}$-measured

-.- $S_{46}$-measured

(a)

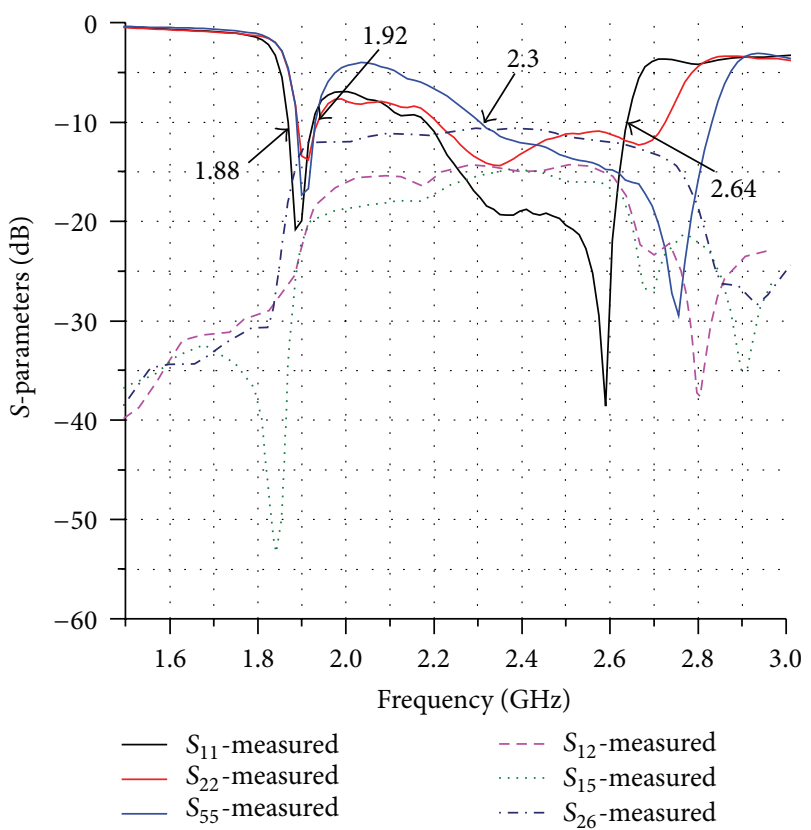

(b)

FIgURE 12: The $S$-parameters of six-element MIMO system.

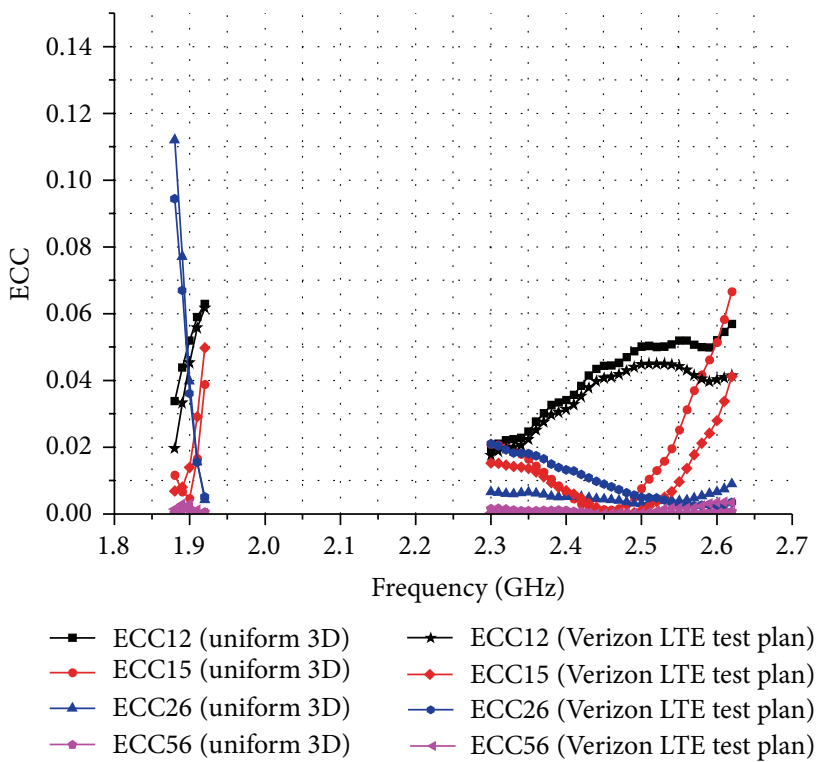

Figure 13: The ECC of six-element MIMO system. 

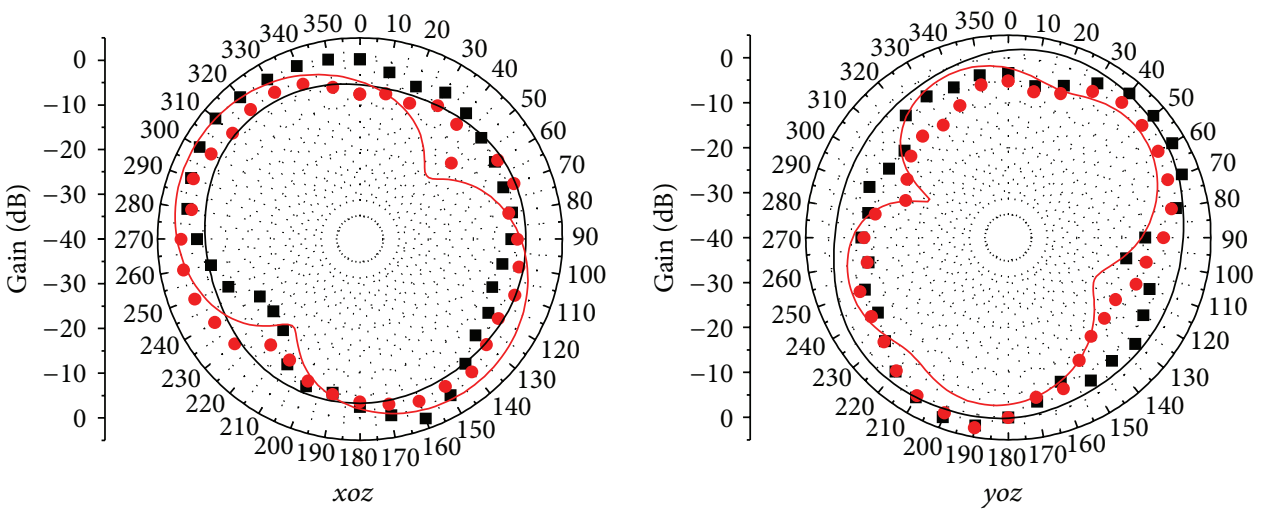

Antenna $1(1.9 \mathrm{GHz})$
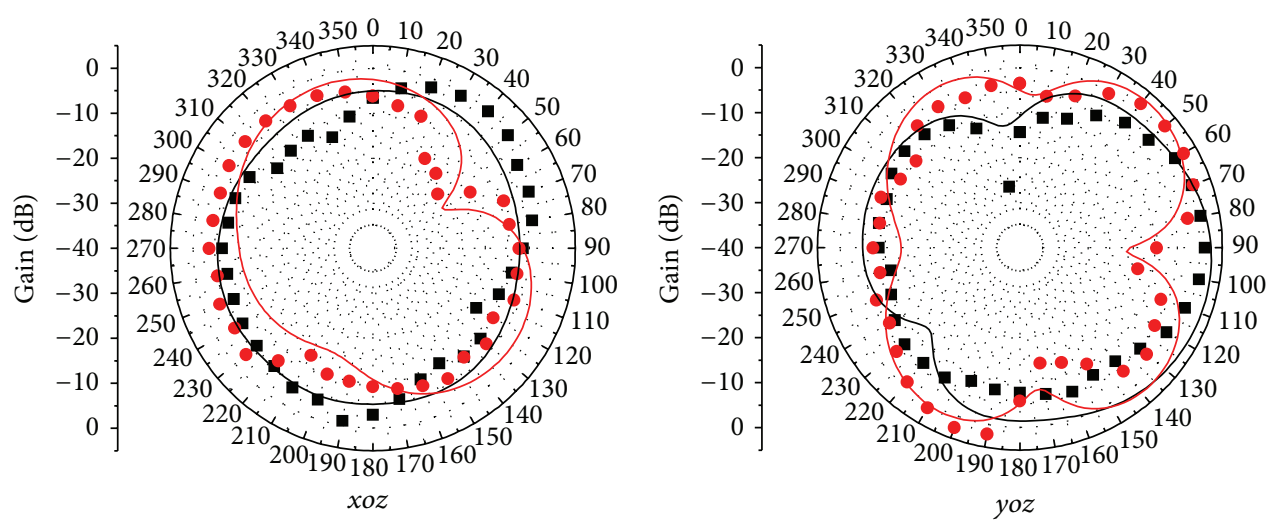

Antenna $2(1.9 \mathrm{GHz})$
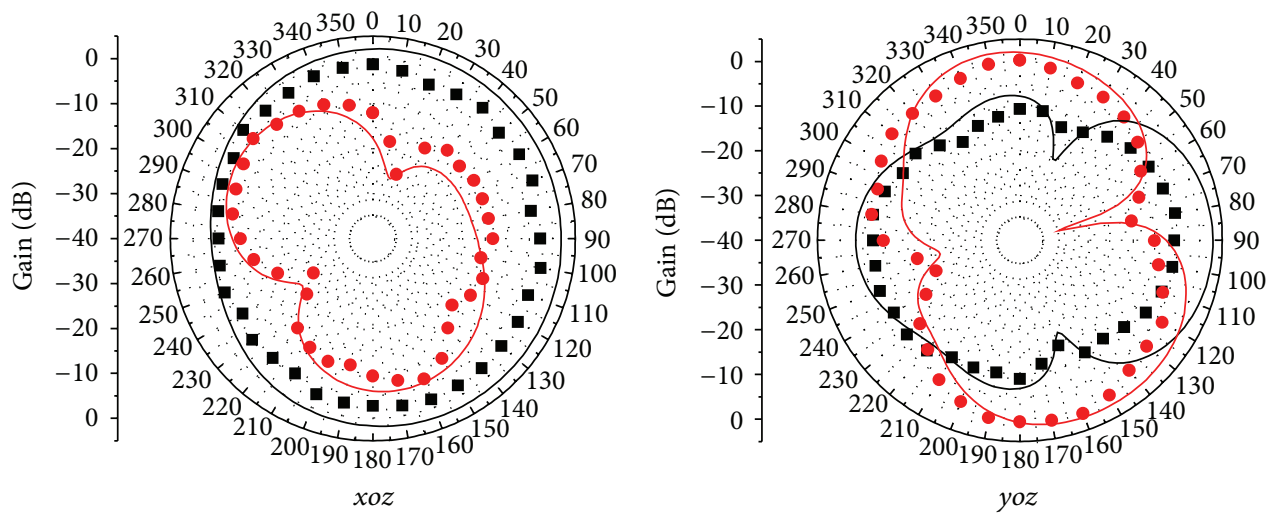

Antenna $5(1.9 \mathrm{GHz})$
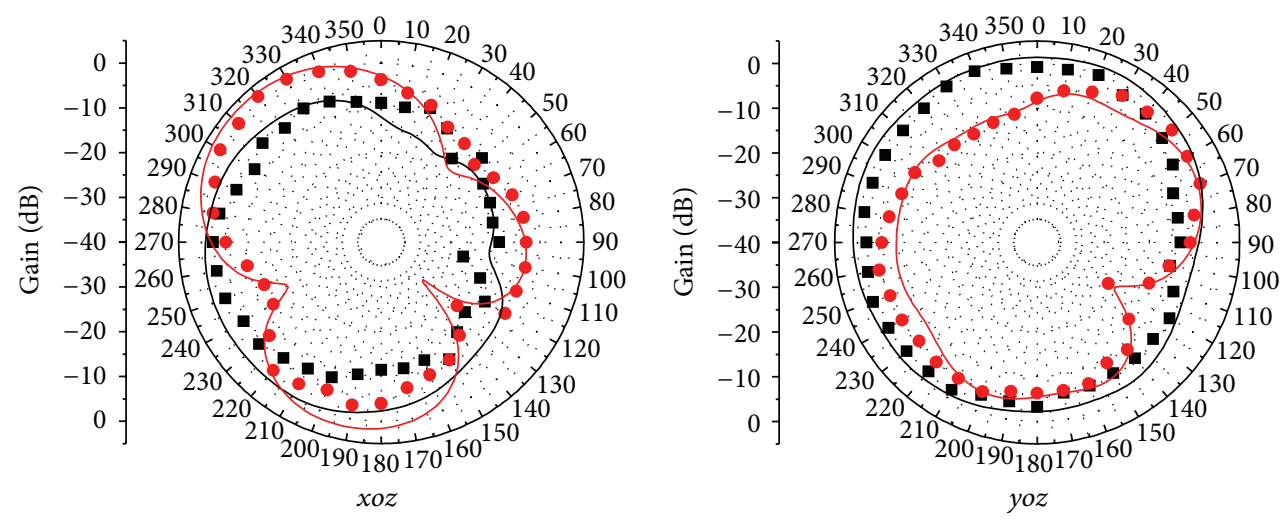

Antenna $1(2.6 \mathrm{GHz})$

Figure 14: Continued. 

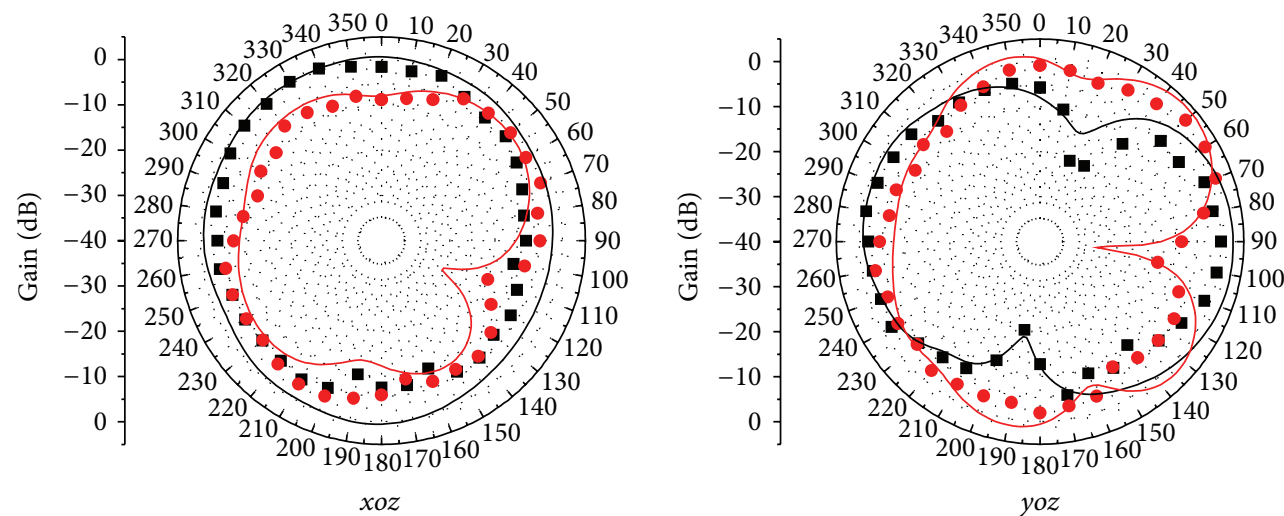

Antenna $2(2.6 \mathrm{GHz})$
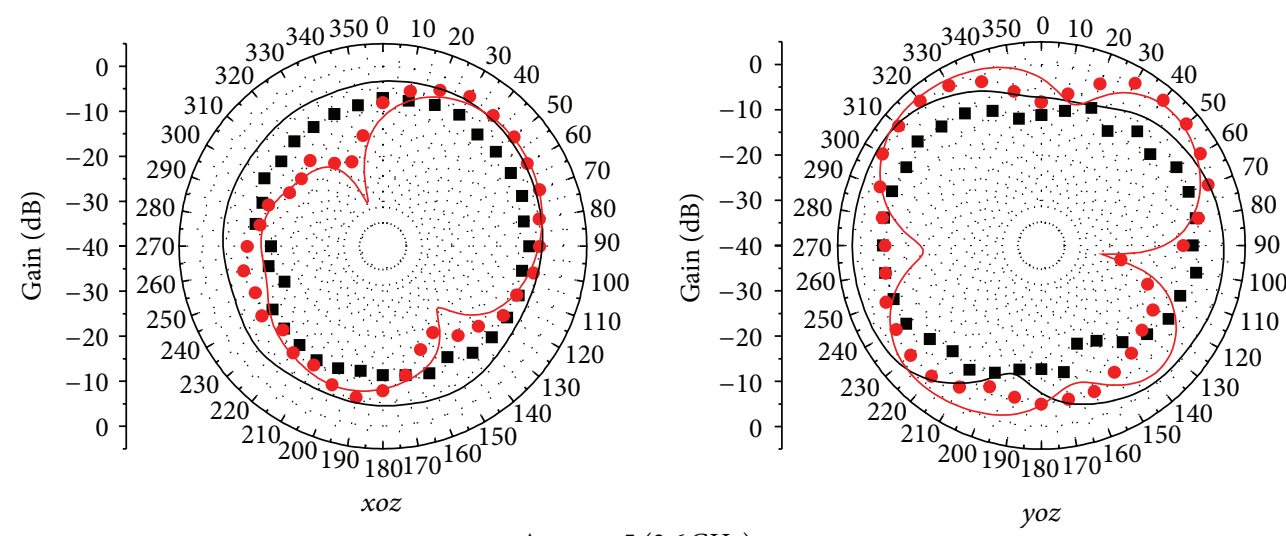

Antenna $5(2.6 \mathrm{GHz})$

$$
\begin{aligned}
& \text { - } G_{\varphi} \text {-measured } \\
& \text { - } G_{\varphi} \text {-simulated } \\
& \text { - } G_{\theta} \text {-measured }
\end{aligned}
$$

FIGURE 14: Measured and simulated radiation patterns of antennas 1, 2, and 5 at $1.9 \mathrm{GHz}$ and $2.6 \mathrm{GHz}$.

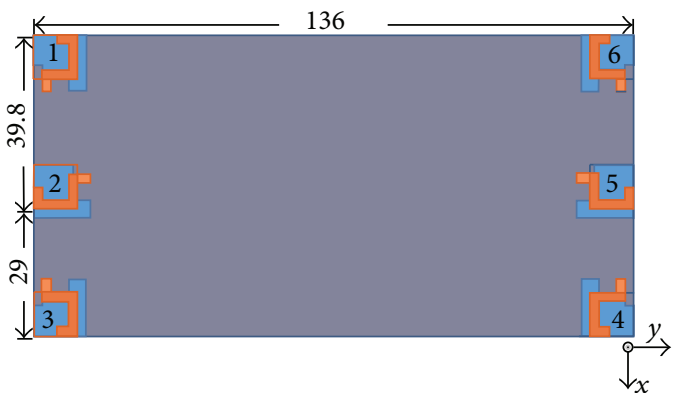

Unit: (mm)

FIGURE 15: The structure of antennas.

the photograph of the fabricated system of Figure 10(b). In this case, all $S$-parameters meet the practical requirements as indicated by Figure 12(b).

Figure 13 shows the envelope correlation coefficients for the MIMO system rotationally symmetric about $z$-axis. Two scenarios have also been considered.

Figure 14 shows the simulated and measured radiation patterns of antennas 1,2 , and 5 at $1.9 \mathrm{GHz}$ and $2.6 \mathrm{GHz}$. The
TABLE 3: Mean effective gains of the antennas.

\begin{tabular}{lcccc}
\hline Frequency $(\mathrm{GHz})$ & $\Gamma(\mathrm{dB})$ & $\begin{array}{c}\text { MEG1 } \\
(\mathrm{dBi})\end{array}$ & $\begin{array}{c}\text { MEG2 } \\
(\mathrm{dBi})\end{array}$ & $\begin{array}{c}\text { MEG5 } \\
(\mathrm{dBi})\end{array}$ \\
\hline \multirow{2}{*}{1.9} & 0 & -6.5 & -4.6 & -6.8 \\
& 6 & -6.1 & -4.8 & -7.2 \\
\hline \multirow{2}{*}{2.6} & 0 & -5.5 & -6.7 & -8.1 \\
& 6 & -5.4 & -6.6 & -7.6 \\
\hline
\end{tabular}

TABle 4: Antenna efficiency.

\begin{tabular}{cccc}
\hline \multicolumn{2}{c}{ Frequency $(\mathrm{GHz})$} & Efficiency $(\%)$ & Multiplexing efficiency $(\mathrm{dB})$ \\
\hline \multirow{2}{*}{1.9} & Antenna 1 & 37 & \\
& Antenna 2 & 50 & -6.71 \\
& Antenna 5 & 44 & \\
\hline \multirow{2}{*}{2.6} & Antenna 1 & 68 & -5.74 \\
& Antenna 2 & 65 & \\
& Antenna 5 & 79 & \\
\hline
\end{tabular}

mean effective gain of each antenna element can be calculated according to the measured radiation pattern and (2) (see Table 3). Table 4 is the measured efficiencies of the antenna elements and the multiplexing efficiencies. 
TABLE 5: Mean effective gains of the antennas.

\begin{tabular}{lcccc}
\hline Frequency $(\mathrm{GHz})$ & $\Gamma(\mathrm{dB})$ & $\begin{array}{c}\text { MEG1 } \\
(\mathrm{dBi})\end{array}$ & $\begin{array}{c}\text { MEG2 } \\
(\mathrm{dBi})\end{array}$ & $\begin{array}{c}\text { MEG3 } \\
(\mathrm{dBi})\end{array}$ \\
\hline \multirow{2}{*}{1.9} & 0 & -7.1 & -8 & -7.9 \\
& 6 & -6.6 & -7.8 & -7.4 \\
\hline \multirow{2}{*}{2.6} & 0 & -7.1 & -6 & -7.8 \\
& 6 & -7 & -7.3 & -7.7 \\
\hline
\end{tabular}

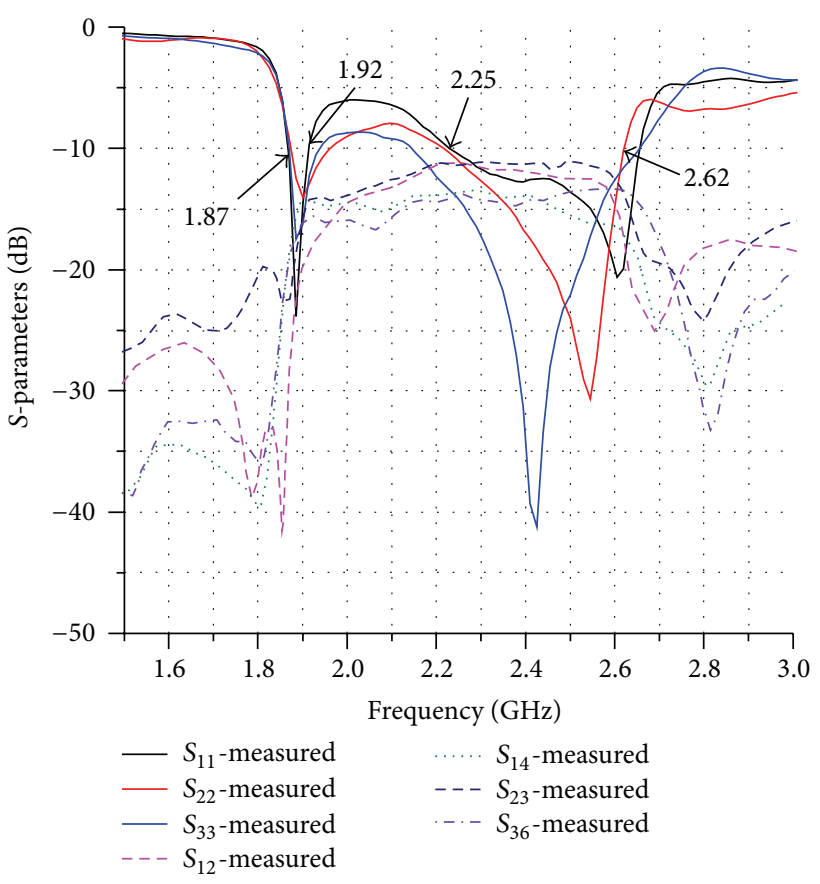

FIgURE 16: The $S$-parameters of antennas 1, 2, and 3.

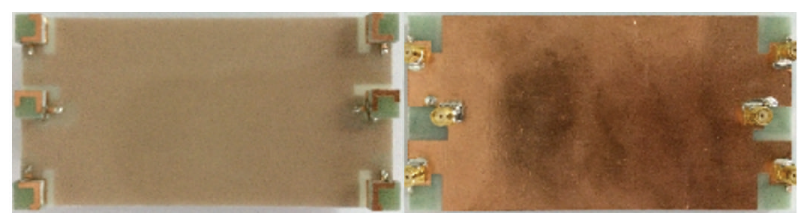

Figure 17: Photograph of the fabricated MIMO antenna system.

As the second arrangement, we move the two middle antenna elements along the long sides to middle position of the short sides, as shown in Figure 15. This arrangement may reduce the influence of human hands on the antennas. Figure 16 shows the measured $S$-parameters. It is noted that all the isolations are less than $-10 \mathrm{~dB}$. Figure 17 is the photograph of the fabricated MIMO system.

Figure 18 shows the envelope correlation coefficients of antennas 1, 2, and 3 in two scenarios, which are less than 0.16 across the frequency bands. The radiation patterns of the antenna elements at $1.9 \mathrm{GHz}$ and $2.6 \mathrm{GHz}$ are shown in Figure 19, from which the MEGs of the antenna elements can be obtained and are listed in Table 5. The efficiencies are measured at two frequencies shown in Table 6. Note that the lowest efficiency is about the same with [47], which has
TABLE 6: Antenna efficiency.

\begin{tabular}{cccc}
\hline \multicolumn{2}{c}{ Frequency $(\mathrm{GHz})$} & Efficiency $(\%)$ & Multiplexing efficiency $(\mathrm{dB})$ \\
\hline \multirow{3}{*}{1.9} & Antenna 1 & 39 & \\
& Antenna 2 & 53 & -7.71 \\
& Antenna 3 & 44 & \\
\hline \multirow{2}{*}{2.6} & Antenna 1 & 66 & -6.22 \\
& Antenna 2 & 59 & \\
& Antenna 3 & 72 & \\
\hline
\end{tabular}

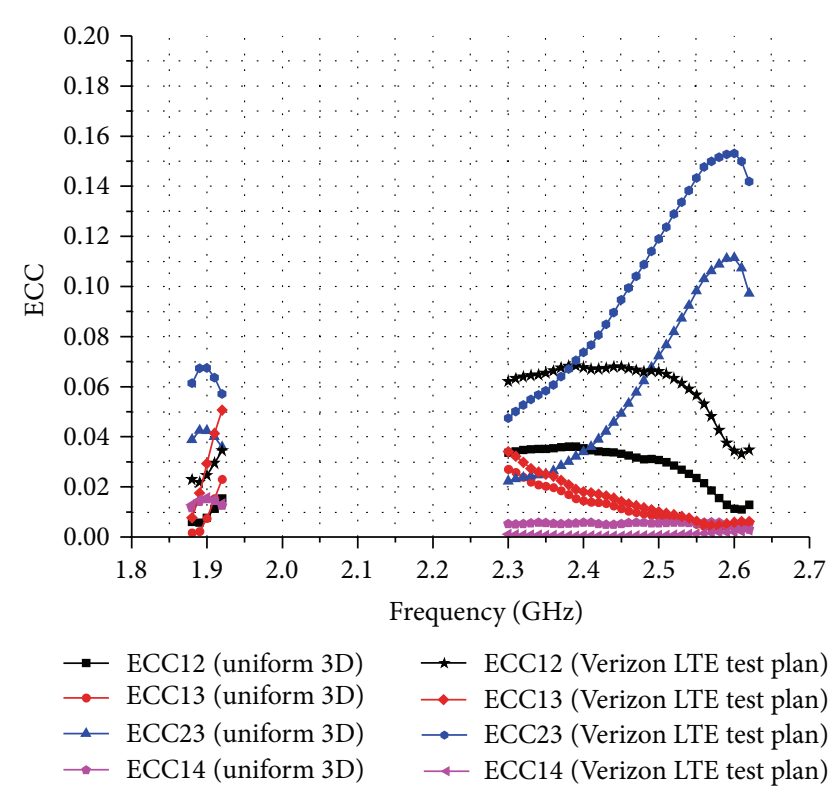

Figure 18: The ECC of antennas 1,2, and 3.

only two elements. Also note that the efficiencies for the second arrangement are generally lower than those for the first arrangement due to the fact that the antenna elements are closer to each other and the power absorption by adjacent elements increases. The multiplexing efficiencies are also shown in Table 6.

Compared with the four-element MIMO arrays, the performances of the six-element MIMO arrays are also acceptable, which implies that a higher capacity can be achieved with more antenna elements. The impact of human body is also an important factor to be considered in the design of handheld devices and have been discussed by many authors (e.g., [48]). In general, the human body will affect various aspects of the performances of the MIMO system, especially degrading the efficiencies of the system.

\section{Conclusion}

Three kinds of MIMO antenna systems for mobile handheld devices have been investigated in this paper, which are compact in size and cover GSM1900, LTE2300, LTE2500, and WLAN 2.4-GHz for the $5 \mathrm{G}$ handset application. The three MIMO systems, all built on a FR4 PCB of small form factor with the size $136 \mathrm{~mm} \times 68.8 \mathrm{~mm} \times 1 \mathrm{~mm}$, consist of four or six three-dimensional planar inverted-F antenna elements 

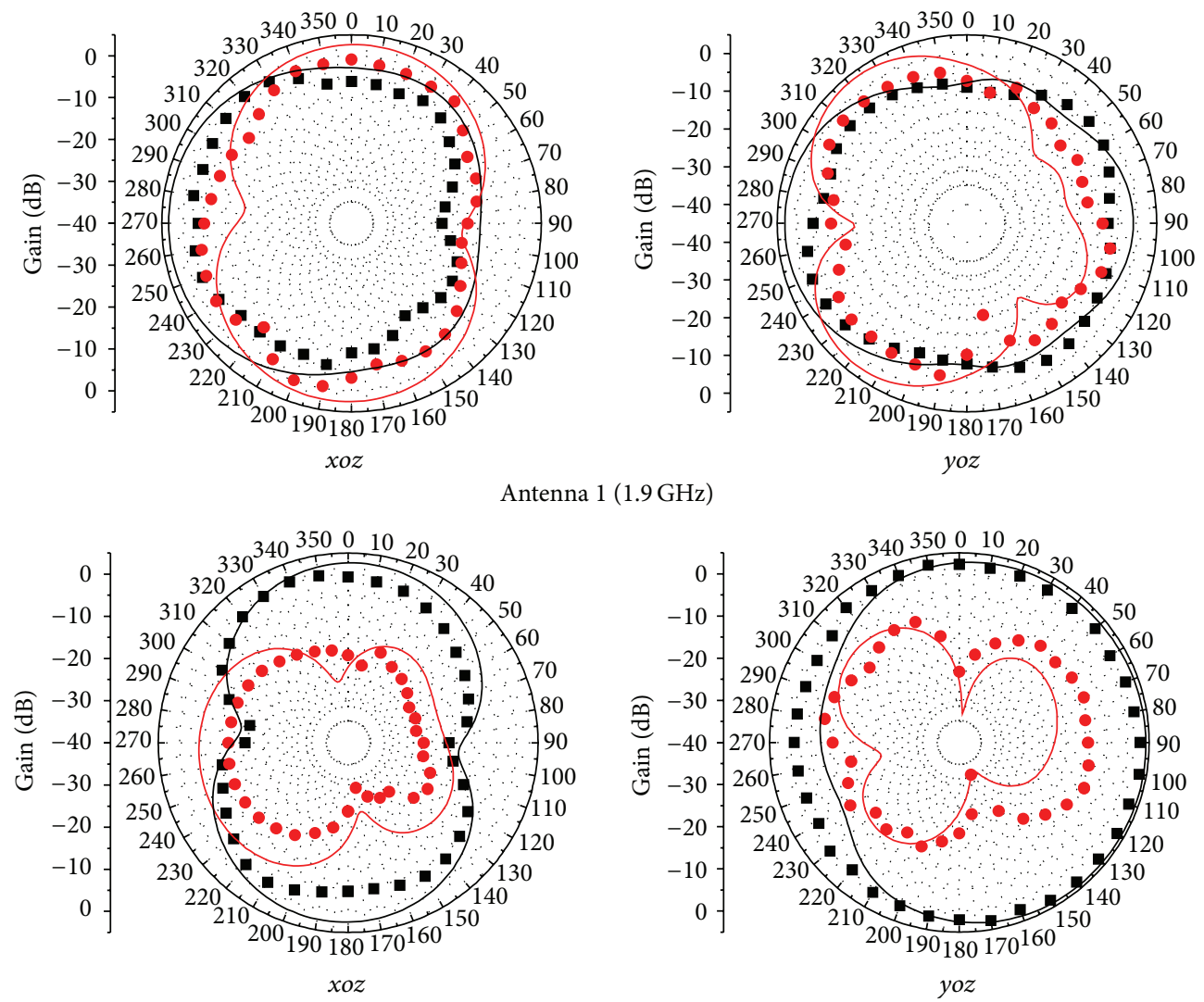

Antenna 2 (1.9 GHz)
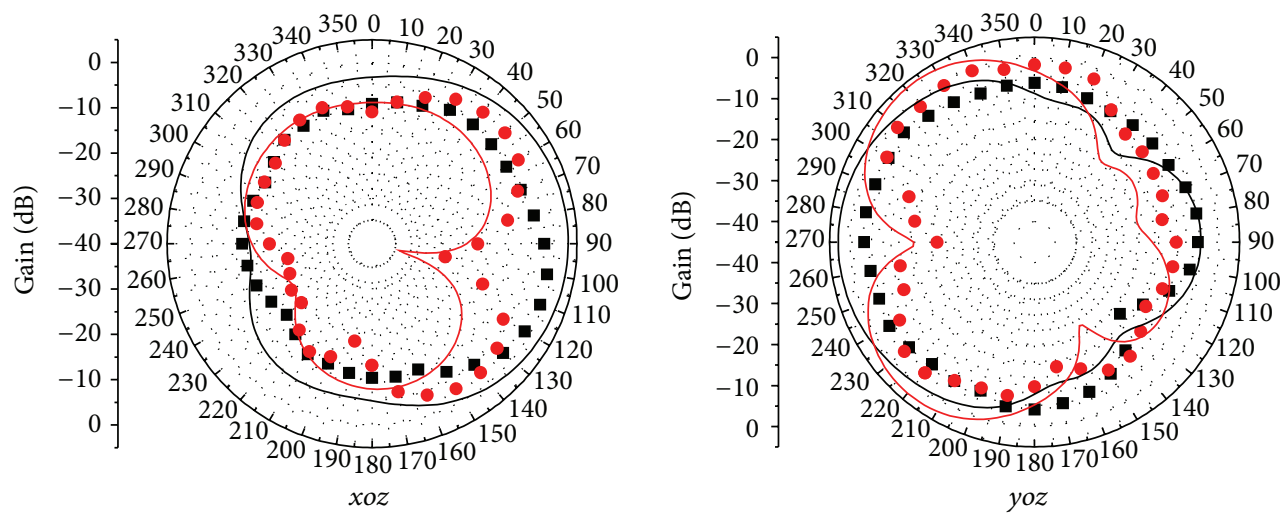

Antenna $3(1.9 \mathrm{GHz})$
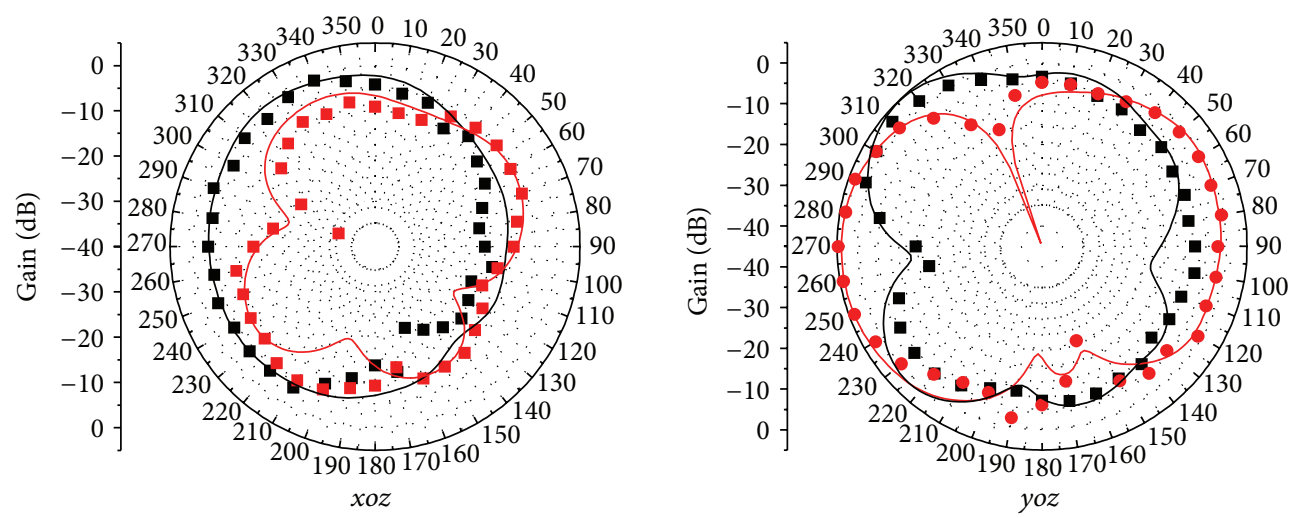

Antenna $1(2.6 \mathrm{GHz})$

Figure 19: Continued. 

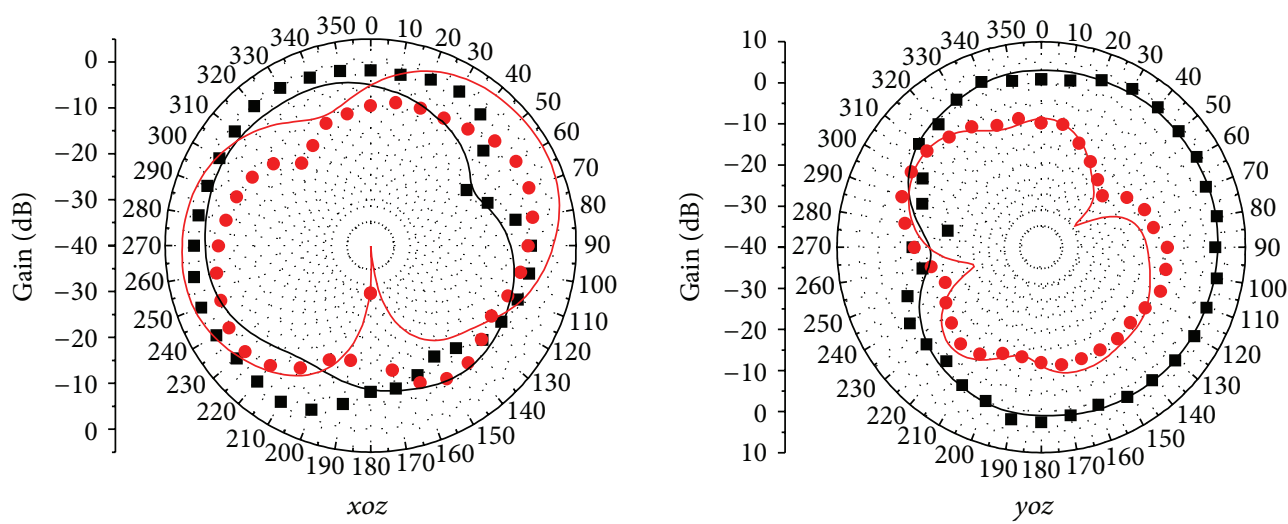

Antenna $2(2.6 \mathrm{GHz})$
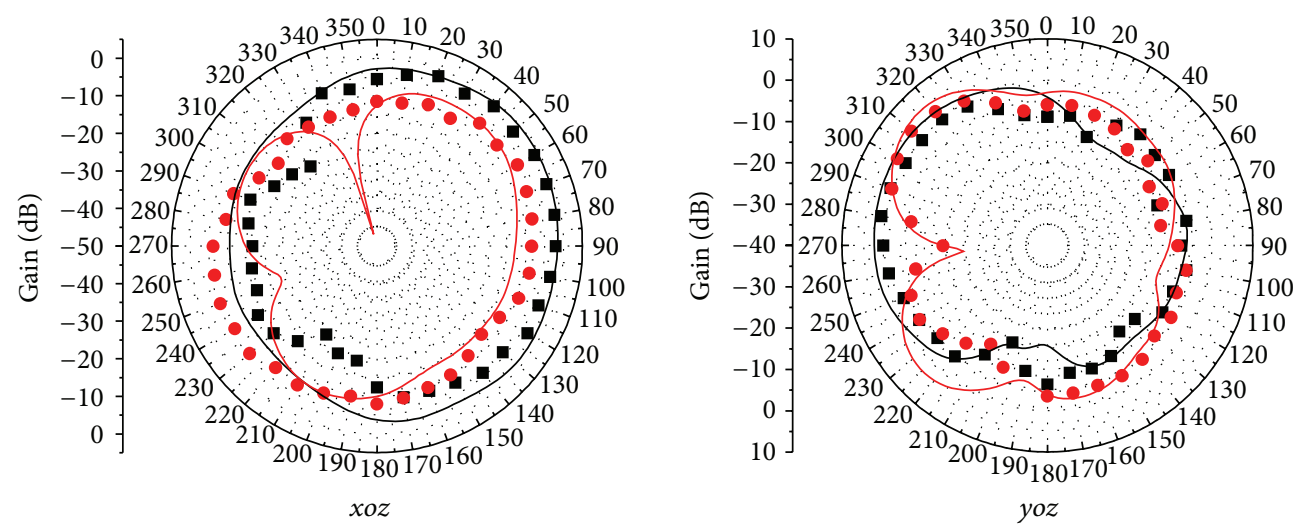

Antenna $3(2.6 \mathrm{GHz})$

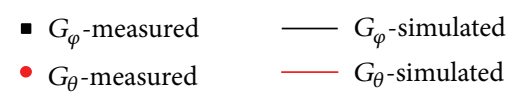

$$
\begin{aligned}
& \text { - } G_{\varphi} \text {-measured } \quad-G_{\varphi} \text {-simulated } \\
& \text { - } G_{\theta} \text {-measured } \quad-G_{\theta} \text {-simulated }
\end{aligned}
$$

FIGURE 19: Measured and simulated radiation patterns of antennas 1, 2, and 3 at $1.9 \mathrm{GHz}$ and $2.6 \mathrm{GHz}$.

wound on a dielectric cube of the size $10 \mathrm{~mm} \times 10 \mathrm{~mm} \times$ $5 \mathrm{~mm}$ (the smallest volume occupied by the antenna that has been reported so far) with relative permittivity 4.4. Different configurations of antenna elements have been examined. The pattern diversity has been used in all our designs and the isolations are higher than $10 \mathrm{~dB}$ without using any decoupling circuits. The ECCs are very small according to the measured data, and the MEGs meet the design requirements that the difference of MEGs between elements must be less than $3 \mathrm{~dB}$. The effects of different element number on the performance are discussed. It reveals that the antenna efficiencies depend on the number of antenna elements as well as the separation between them. The antenna efficiency will degrade if the number of elements increases or if the separation between them decreases. These seem to be the big challenges for the design of MIMO system packed in a small space.

\section{Conflict of Interests}

The authors declare that there is no conflict of interests regarding the publication of this paper.

\section{Acknowledgments}

This work was supported in part by the Jiangsu Innovation \& Entrepreneurship Group Talents Plan and in part by a grant from Huawei Technologies Co. Ltd.

\section{References}

[1] X. Chen, S. Shoaib, I. Shoaib, N. Shoaib, and C. G. Parini, "MIMO antennas for mobile handsets," IEEE Antennas and Wireless Propagation Letters, vol. 14, pp. 799-802, 2015.

[2] X. Zhao and J. Choi, "Multiband MIMO antenna for 4G mobile terminal," in Proceedings of the IEEE Asia-Pacific Microwave Conference (APMC '13), pp. 41-59, Seoul, South Korea, November 2013.

[3] K. Zhao, S. Zhang, S. He, K. Ishimiya, and Z. Ying, "Bodyinsensitive multimode MIMO terminal antenna of double-ring structure," IEEE Transactions on Antennas and Propagation, vol. 63, no. 5, pp. 1925-1936, 2015.

[4] A. Toktas and A. Akdagli, "Wideband MIMO antenna with enhanced isolation for LTE, WiMAX and WLAN mobile handsets," Electronics Letters, vol. 50, no. 10, pp. 723-724, 2014. 
[5] Y. Ding, Z. Du, K. Gong, and Z. Feng, "A novel dual-band printed diversity antenna for mobile terminals," IEEE Transactions on Antennas and Propagation, vol. 55, no. 7, pp. 2088-2096, 2007.

[6] K.-S. Min, D.-J. Kim, and M.-S. Kim, "Multi-channel MIMO antenna design for WiBro/PCS band," in Proceedings of the IEEE Antennas and Propagation Society International Symposium (APS '07), pp. 1225-1228, IEEE, Honolulu, Hawaii, USA, June 2007.

[7] I. P. Kovalyov and D. M. Ponomarev, "Small-size 6-port antenna for three-dimensional multipath wireless channels," IEEE Transactions on Antennas and Propagation, vol. 54, no. 12, pp. 3746-3754, 2006.

[8] W. Li, "A compact MIMO antenna used for LTE terminals with high isolation," in Proceedings of the IEEE 5th International Symposium on Microwave, Antenna, Propagation and EMC Technologies for Wireless Communications (MAPE '13), pp. 308310, Chengdu, China, October 2013.

[9] S. Shoaib, I. Shoaib, N. Shoaib, X. Chen, and C. G. Parini, "A 4x4 MIMO antenna system for mobile tablets," in Proceedings of the 8th European Conference on Antennas and Propagation (EuCAP '14), pp. 2813-2816, The Hague, The Netherlands, April 2014.

[10] B. Lee, F. J. Harackiewicz, and H. Wi, "Closely mounted mobile handset MIMO antenna for LTE 13 band application," IEEE Antennas and Wireless Propagation Letters, vol. 13, pp. 411-414, 2014.

[11] S. Zhang, Z. Ying, and S. He, "Diagonal chassis mode for mobile handset LTE MIMO antennas and its application to correlation reduction," in Proceedings of the 3rd IEEE International Workshop on Electromagnetics Applications and Student Innovation (IWEM '12), pp. 1-2, IEEE, Chengdu, China, August 2012.

[12] Q. Rao and D. Wang, "A compact dual-port diversity antenna for long-term evolution handheld devices," IEEE Transactions on Vehicular Technology, vol. 59, no. 3, pp. 1319-1329, 2010.

[13] A.-D. Capobianco, F. M. Pigozzo, A. Assalini, M. Midrio, S. Boscolo, and F. Sacchetto, "A compact MIMO array of planar end-fire antennas for WLAN applications," IEEE Transactions on Antennas and Propagation, vol. 59, no. 9, pp. 3462-3465, 2011.

[14] A. C. K. Mak, C. R. Rowell, and R. D. Murch, "Isolation enhancement between two closely packed antennas," IEEE Transactions on Antennas and Propagation, vol. 56, no. 11, pp. 3411-3419, 2008.

[15] C.-C. Hsu, K.-H. Lin, and H.-L. Su, "Implementation of broadband isolator using metamaterial-inspired resonators and a T-shaped branch for MIMO antennas," IEEE Transactions on Antennas and Propagation, vol. 59, no. 10, pp. 3936-3939, 2011.

[16] P. J. Ferrer, J. M. González-Arbesú, and J. Romeu, "Decorrelation of two closely spaced antennas with a metamaterial AMC surface," Microwave and Optical Technology Letters, vol. 50, no. 5, pp. 1414-1417, 2008.

[17] S.-C. Chen, Y.-S. Wang, and S.-J. Chung, "A decoupling technique for increasing the port isolation between two strongly coupled antennas," IEEE Transactions on Antennas and Propagation, vol. 56, no. 12, pp. 3650-3658, 2008.

[18] C.-Y. Chiu, C.-H. Cheng, R. D. Murch, and C. R. Rowell, "Reduction of mutual coupling between closely-packed antenna elements," IEEE Transactions on Antennas and Propagation, vol. 55, no. 6, pp. 1732-1738, 2007.

[19] S. Kahng, J. Jeon, J. Anguera, and T. Park, "A compact MIMO antenna using CRLH configuration double-layered folded ring radiations with planar mushroom decoupling structure," IEEE
Antennas and Propagation Magazine, vol. 57, no. 2, pp. 123-130, 2015.

[20] I. Szini, A. Tatomirescu, and G. F. Pedersen, "On small terminal MIMO antennas, harmonizing characteristic modes with ground plane geometry," IEEE Transactions on Antennas and Propagation, vol. 63, no. 4, pp. 1487-1497, 2015.

[21] J.-F. Li, Q.-X. Chu, and T.-G. Huang, "A compact wideband MIMO antenna with two novel bent slits," IEEE Transactions on Antennas and Propagation, vol. 60, no. 2, pp. 482-489, 2012.

[22] F. Ahmed, Y. Feng, and R. Li, "Dual wide-band four-unit MIMO antenna system for 4G/LTE and WLAN mobile phone applications," in Proceedings of the Loughborough Antennas and Propagation Conference (LAPC '13), pp. 202-207, Loughborough, UK, November 2013.

[23] S. Shoaib, I. Shoaib, N. Shoaib, X. Chen, and C. G. Parini, "Design and performance study of a dual-element multiband printed monopole antenna array for MIMO terminals," IEEE Antennas and Wireless Propagation Letters, vol. 13, pp. 329-332, 2014.

[24] M.-S. Han and J. Choi, "MIMO antenna using a decoupling network for next generation mobile application," in Proceedings of the 9th International Symposium on Communications and Information Technology (ISCIT '09), pp. 568-571, IEEE, Icheon, The Republic of Korea, September 2009.

[25] J.-M. Lee, K.-B. Kim, H.-K. Ryu, and J.-M. Woo, "A compact ultrawideband MIMO antenna with WLAN band-rejected operation for mobile devices," IEEE Antennas and Wireless Propagation Letters, vol. 11, pp. 990-993, 2012.

[26] H. Wang, D. G. Fang, and X. L. Wang, "Mutual coupling reduction between two microstrip patch antennas by using the parasitic elements," in Proceedings of the Asia Pacific Microwave Conference (APMC '08), pp. 1-4, Macau, China, December 2008.

[27] G. Li, H. Zhai, Z. Ma, C. Liang, R. Yu, and S. Liu, "Isolationimproved dual-band MIMO antenna array for LTE/WiMAX mobile terminals," IEEE Antennas and Wireless Propagation Letters, vol. 13, pp. 1128-1131, 2014.

[28] D. F. Kelley and W. L. Stutzman, "Array antenna pattern modeling methods that include mutual coupling effects," IEEE Transactions on Antennas and Propagation, vol. 41, no. 12, pp. 1625-1632, 1993.

[29] V. Ssorin, A. Artemenko, A. Sevastyanov, and R. Maslennikov, "Compact bandwidth-optimized two element MIMO antenna system for 2.5-2.7 GHz band," in Proceedings of the 5th European Conference on Antennas and Propagation (EUCAP '1), pp. 319323, Rome, Italy, April 2011.

[30] Q. Rao and W. Geyi, "Compact multiband antenna for handheld devices," IEEE Transactions on Antennas and Propagation, vol. 57, no. 10, pp. 3337-3339, 2009.

[31] W. Geyi, Q. Rao, S. Ali, and D. Wang, "Handset antenna design: practice and theory," Progress in Electromagnetics Research, vol. 80, pp. 123-160, 2008.

[32] S. Stein, "On cross coupling in multiple-beam antennas," IRE Transactions on Antennas and Propagation, vol. 10, no. 5, pp. 548-557, 1962.

[33] I. Salonen and P. Vainikainen, "Estimation of signal correlation in antenna arrays," in Proceedings of the 12th International Symposium on Antenna (JINA '02), vol. 2, pp. 383-386, Nice, France, November 2002.

[34] S. Blanch, J. Romeu, and I. Corbella, "Exact representation of antenna system diversity performance from input parameter description," Electronics Letters, vol. 39, no. 9, pp. 705-707, 2003. 
[35] R. G. Vaughan and J. B. Andersen, "Antenna diversity in mobile communications," IEEE Transactions on Vehicular Technology, vol. 36, no. 4, pp. 149-172, 1987.

[36] J. P. Kermoal, L. Schumacher, K. I. Pedersen, P. E. Mogensen, and F. Frederiksen, "A stochastic MIMO radio channel model with experimental validation," IEEE Journal on Selected Areas in Communications, vol. 20, no. 6, pp. 1211-1226, 2002.

[37] Q. Yao, Y. Yuan, A. Ghazal, C.-X. Wang, L. Luan, and X. Lu, "Comparison of the statistical properties of the LTE-A and IMT-A channel models," in Proceedings of the IEEE Wireless Communications and Networking Conference (WCNC '12), pp. 393-398, IEEE, Shanghai, China, April 2012.

[38] A. Jassal, H. Khanfir, and S. Martinez Lopez, "Preliminary system-level simulation results for the 3GPP 3D MIMO channel model," in Proceedings of the IEEE 80th Vehicular Technology Conference (VTC-Fall '14), pp. 1-5, Vancouver, Canada, September 2014.

[39] G. F. Pedersen and J. B. Andersen, "Handset antennas for mobile communications: integration, diversity and performance," in Review of Radio Science, pp. 119-138, Oxford University Press, Oxford, UK, 1999.

[40] G. Kang, Z. Du, and K. Gong, "Novel compact quasi-dipole diversity antenna for mobile terminals," IEEE Antennas and Wireless Propagation Letters, vol. 10, pp. 1166-1169, 2011.

[41] T. Taga, "Analysis for mean effective gain of mobile antennas in land mobile radio environments," IEEE Transactions on Vehicular Technology, vol. 39, no. 2, pp. 117-131, 1990.

[42] S. C. K. Ko and R. D. Murch, "Compact integrated diversity antenna for wireless communications," IEEE Transactions on Antennas and Propagation, vol. 49, no. 6, pp. 954-960, 2001.

[43] Y. Wang and Z. Du, "A printed dual-antenna system operating in the GSM1800/GSM1900/UMTS/ LTE2300/LTE2500/2.4 GHz WLAN bands for mobile terminals," IEEE Antennas and Wireless Propagation Letters, vol. 13, pp. 233-236, 2014.

[44] R. Tian, B. K. Lau, and Z. Ying, "Multiplexing efficiency of MIMO antennas," IEEE Antennas and Wireless Propagation Letters, vol. 10, pp. 183-186, 2011.

[45] R. Tian, B. K. Lau, and Z. Ying, "Multiplexing efficiency of MIMO antennas in arbitrary propagation scenarios," in Proceedings of the 6th European Conference on Antennas and Propagation (EuCAP '12), pp. 373-377, IEEE, Prague, Czech Republic, March 2012.

[46] R. Vaughan and J. B. Andersen, Channels, Propagation and Antennas for Mobile Communications, Institution of Electrical Engineers (IEE), London, UK, 2003.

[47] S. Wang and Z. Du, "Decoupled dual-antenna system using crossed neutralization lines for LTE/WWAN smartphone applications," IEEE Antennas and Wireless Propagation Letters, vol. 14, pp. 523-526, 2015.

[48] K. Zhao, S. Zhang, Z. Ying, and S. He, "MIMO performance study of different antennas for LTE mobile phones in CTIA test mode," in Proceedings of the 7th European Conference on Antennas and Propagation (EuCAP '13), pp. 727-731, Gothenburg, Sweden, April 2013. 


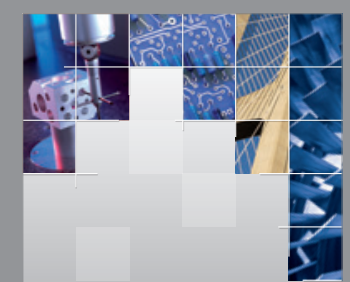

\section{Enfincering}
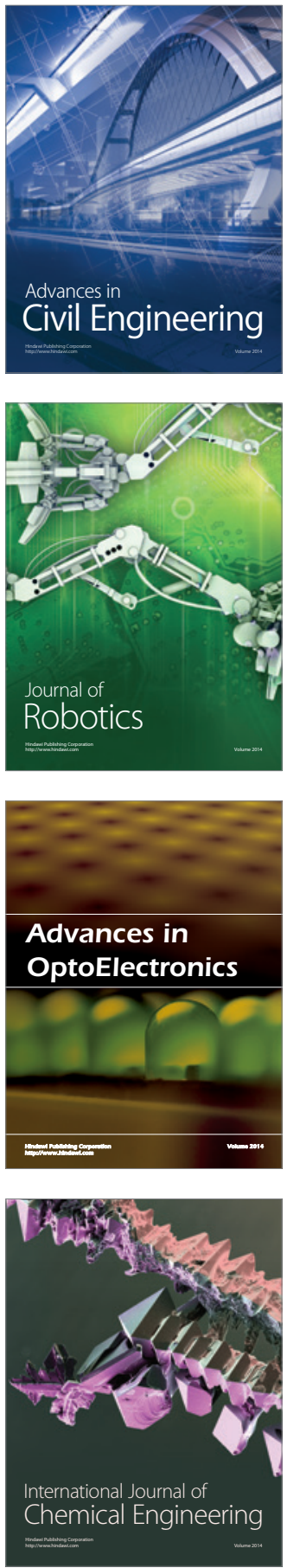

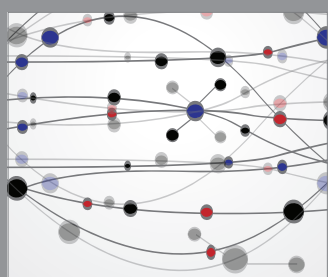

The Scientific World Journal

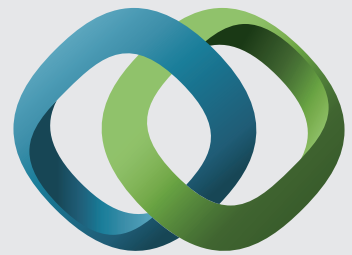

\section{Hindawi}

Submit your manuscripts at

http://www.hindawi.com
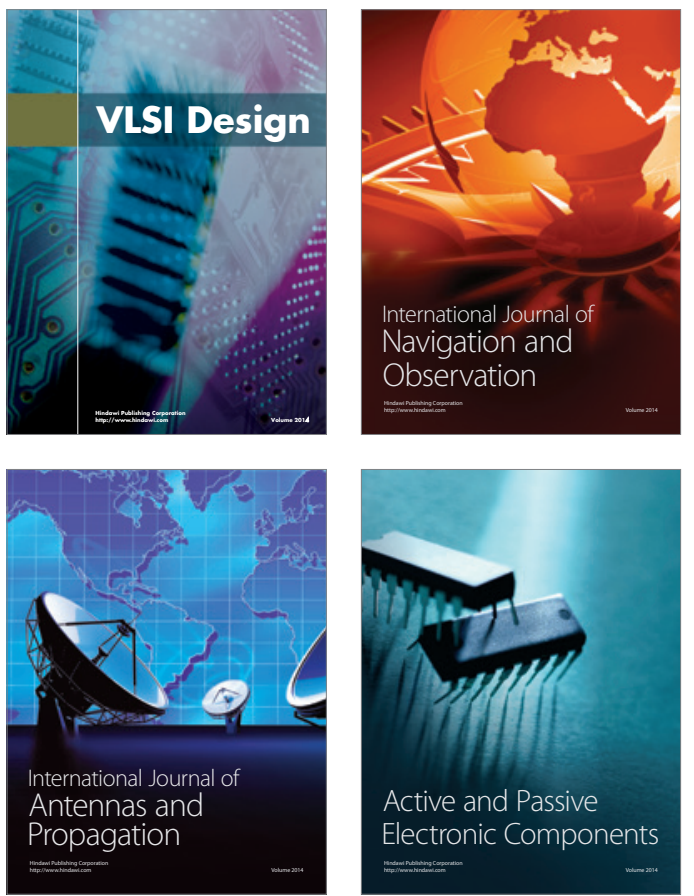
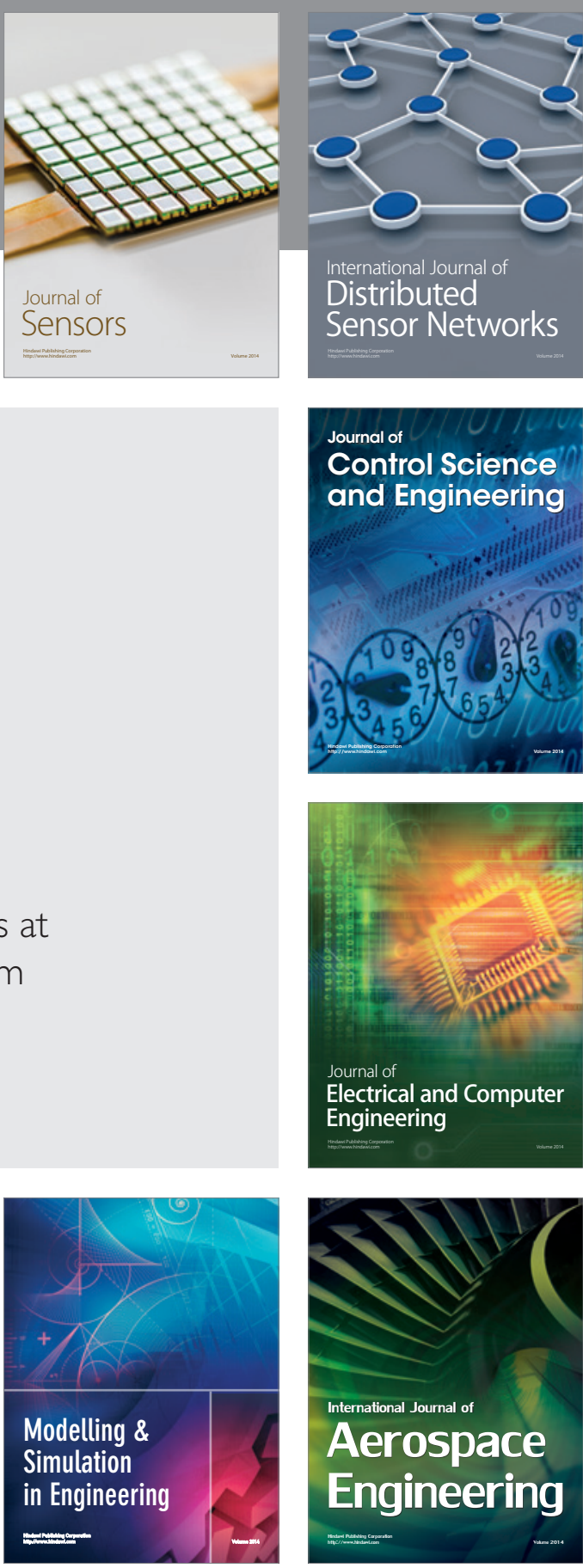

International Journal of

Distributed

Sensor Networks

Journal of

Control Science

and Engineering
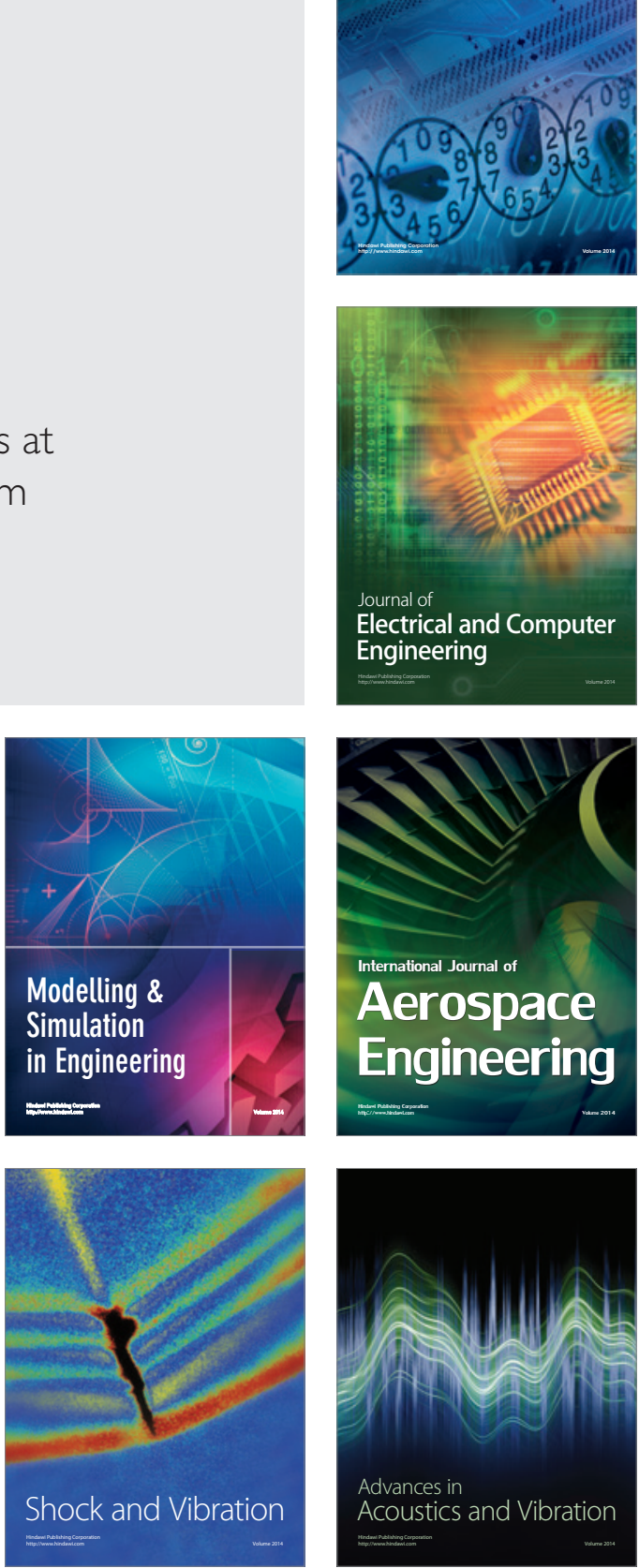